\title{
Road service facilities for improving the ecological state using the PPP mechanism
}

\author{
Artem Subbotin ${ }^{1, *}$ and Sevada Grigoryan ${ }^{1}$ \\ ${ }^{1}$ Moscow state University of civil Engineering, Yaroslavskoe shosse, 26, Moscow, 129337, Russia
}

\begin{abstract}
The relevance of this work is associated with the creation of methodological foundations for the formation of effective organizational forms and ways to improve the quality of road maintenance, the development of conditions that prevent different types of environmental pollution, compliance with environmental protection and environmental safety throughout the length of road transport routes. The study solves the following tasks: analysis of the development of systems and complexes that prevent environmental pollution, the development of road service facilities with the infrastructure for the environmental mode of transport, substantiation of the organizational form and scheme of interaction between the state and private business in the Russian Federation for the implementation of road service facilities, comparison of Russian and international experience in the development of these facilities. The organizational form of construction of road service facilities using the public-private partnership (PPP) mechanism in the Russian Federation is a priority from an economic point of view and effective for the development of facilities that contribute to the improvement and compliance with environmental safety requirements. The most effective type of construction in this industry is modular construction. Combining PPP and modular type of construction is the most priority method of cooperation for private entrepreneurs. The minimum construction time and the availability of the roadside service will accordingly improve the conditions for movement of road users and, thus, the ecological state.
\end{abstract}

\section{Introduction}

Roadside service is a sphere of activity that provides satisfaction of human and vehicle needs in the way (road). This can include any services provided to consumers on the way (on the road) on any form of transport. With the development of roads, there are many problems with its infrastructure. One of these problems is the insufficient number and quality of road services. Because of the presented problem, the ecological state of the environment is deteriorating. Sustainable transportation (ecological) comes on the place of transport with internal combustion engine to reduce environmental pollution. Ecological transport is a type of vehicles for movement with a minimum of environmental pollution. They are bicycles, scooters, electric cars and the like. The infrastructure of road transport routes should be

${ }^{*}$ Corresponding author: subbotin-art@mail.ru 
equipped with additional systems for the efficiency of environmental transport to support the development of this direction and be available in the required quantity. The basis of the infrastructure for the movement of vehicles is road services. Thus, the relevance of this scientific work is the creation of a perspective mechanism for the construction of road services on the example of the use of public-private partnership (PPP) in the Russian Federation in order to improve the environmental state of the environment.

The object of the study is roadside services on the roads.

This article discusses the following key objectives of the study:

- analysis of the development of systems and complexes that prevent environmental pollution;

- development of road service facilities with infrastructure for environmental transport;

- substantiation of the organizational form and scheme of interaction between the state and private business for the implementation of road service facilities;

- comparison of Russian and international experience in the development of roadside service facilities.

\section{Research methods}

It is necessary to conduct a study to determine the need to improve the quality and increase the number of roadside services as a result of which it will be possible to draw a conclusion about the feasibility of developing construction in this direction, which will improve the ecological state in general. Data analysis of the total number of roadside services and their percentage is used as a method for the study. To use environmental transport, and especially cars with an electric motor, you need to analyze and determine the ratio of the number of cars with an electric motor and places for charging these cars. According to the OECD Green Growth Indicators 2017 report, progress in improving the efficiency of using natural resources and reducing the burden on the environment in the world is too slow.

Moreover, the report notes that the level of air pollution remains dangerously high. In particular, less than $1 / 3$ of OECD countries comply with WHO standards. The level of emissions of harmful substances in Russia is significantly higher than in many large countries, which leads to increased risks for the population. Based on this, the Russian Federation is an example of a study. In our case, the materials confirming the data necessary for the study are provided by the Ministry of Transport of the Russian Federation. It is also necessary to analyze the effectiveness of the use of PPP in the process of solving this problem. The interest of private entrepreneurs plays a big role in the implementation of this mechanism. The complex processes of social and economic development of the state make it difficult to perform socially significant issues, so the joint work of the state and private business is relevant. PPP can provide enormous support to the development of the investment and construction complex due to the increased competitiveness of regions and their development. For greater efficiency of this mechanism it is necessary to analyze and compare types of construction. As a result, it is necessary to determine the most effective method of construction. The key factors are the quality, conditions, terms and price of construction.

\section{Research results}

The results of the study show that worldwide work is underway to develop systems that implement environmentally friendly mechanisms. An example of the study in our article is 
the Russian Federation. It can be concluded from the results of the work that at this time the roadside service of Russia is progressing and trying to reach a new level. According to the Ministry of Transport of the Russian Federation, the total number of road service facilities is 6222. The percentage is shown in the diagram:

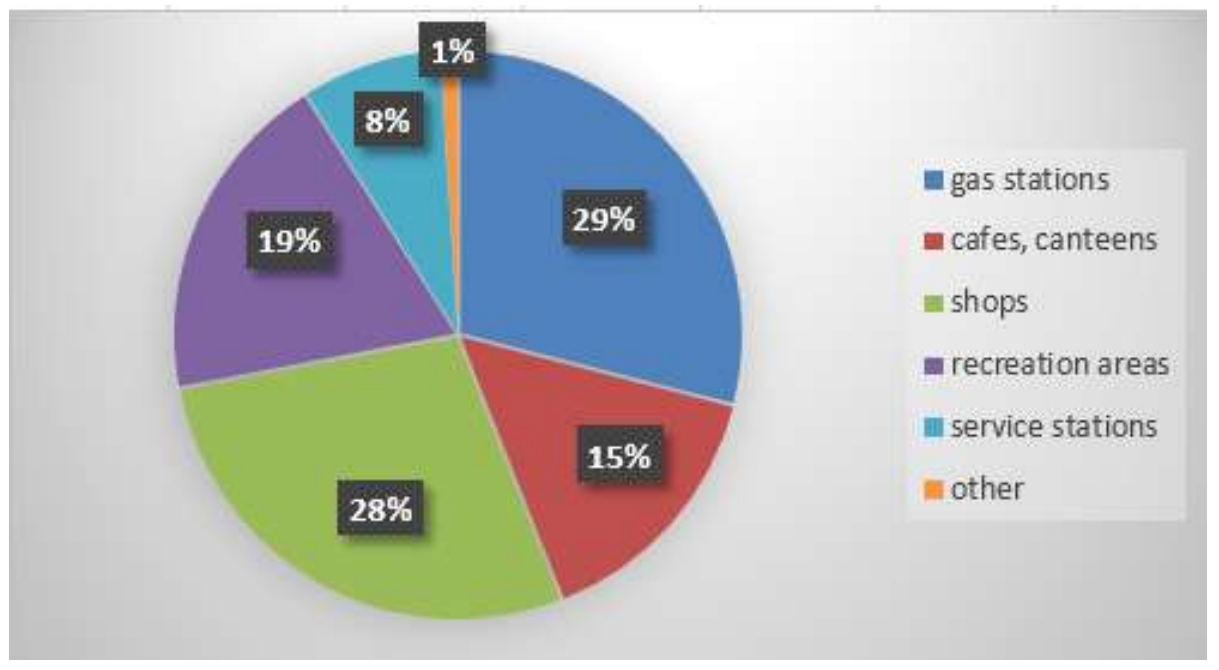

Fig. 1. Chart of the percentage of the UDF.

From the presented data it can be noted that only $15 \%$ of the total number of roadside services are intended for eating, which is a small amount. It follows from this that people are forced to stop on the sidelines and eat because the places to eat are absent. Because of this there are cases when food waste remains at the place of eating, which adversely affects the ecological state of the environment.

International experience shows the desire of countries to switch to the use of environmental transport as soon as possible. In this component, the Russian Federation is just beginning to develop. The number of electric vehicles in Russia according to "AUTOSTAT" for the summer of 2018 - about 2500 units. The number of electric vehicles relative to the regions of Russia is shown in the Fig. 2.

Since the direction of ecological transport is just beginning its development, the charging system for electric vehicles in roadside services is not common, which is a problem for the free use of ecological transport. The number of electric vehicles every year becomes more and more, therefore, the construction of road services equipped with systems for the use of ecological transport will play a positive role in improving the ecological state.

Having studied the data of the Federal State Statistics Service for 2012, we can determine that after 2000 there has been an increase in private companies from $63.9 \%$ to $89 \%$ of all organizations with various forms of ownership. On this basis, it becomes clear that the private sector is the basis of the economy of any developed country, including large and small enterprises. Therefore, state support for private activities is necessary for mutually beneficial cooperation, the purpose of which is the most rational and painless monitoring and adjustment of the country's economic situation. PPP is necessary to create an organizational structure, the purpose of which is the emergence of new infrastructure and production projects, the implementation of the development of investment and construction activities in the region, and accordingly, the construction industry with all related industries. 


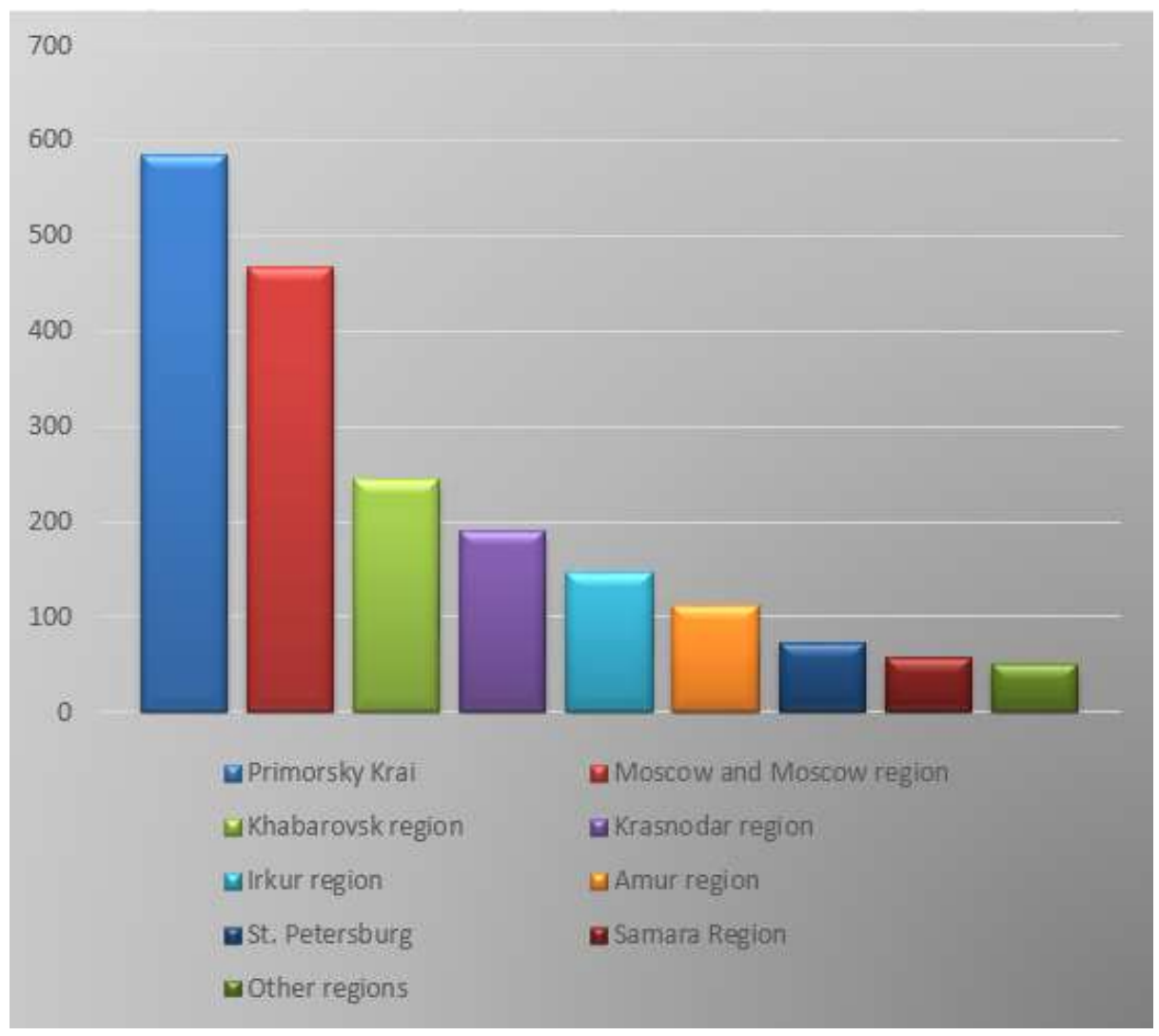

Fig. 2. Number of electric vehicles in Russia.

Analyzing all types of construction, the priority type of construction for the development of road construction complexes is modular construction. This type will provide high-quality, fast and inexpensive construction. Also modular construction is carried out in any conditions.

\section{Conclusion}

Ecology is an important component in our life. Humanity must be aware that it is part of the biosphere and must be careful with nature. In this regard at this stage of our life systems that improve the ecological state in general are being actively developed.

This article also conducted research with the main purpose - to improve the ecological state of the environment. The object of the study was the road transport routes and related road services. The construction of a sufficient number of road services will provide road users with comfortable conditions and the minimum possible damage to the environment. Proper infrastructure that meets the requirements for the operation of environmental transport will provide additional development and agitation of the population to environmental mechanisms. This procedure will significantly reduce the pollution of the environment with exhaust gases, which is a positive result of our work. According to the results of the study, the organizational form of construction of road service facilities using the mechanism of 
public-private partnership in the Russian Federation is a priority from an economic point of view and effective for the development of facilities that contribute to the improvement and compliance with environmental safety requirements. The mechanism of construction on the basis of PPP with the use of a modular type of construction is an innovative technique that serves to combine public and private investments in the implementation of major infrastructure projects. We saw that the presented mechanism will have a positive impact on the development of road services with all the amenities for environmental transport on the example of the Russian Federation. This system has earned great interest from private entrepreneurs, which determines the scale of development of road service to improve the environment.

\section{References}

1. A.S. Subbotin, Scientific review 2, 243-245 (2013)

2. A.S. Subbotin, S.B. Sborschikov, Integration, partnership and innovation in construction science and education: scientific publication (MGSU, Moscow, 2012)

3. A.S. Subbotin, S.B. Sborschikov, Vestnik MGSU 4, 167-171 (2014)

4. W.-M. Wey, Jh.-Y. Huang, Habitat International 82, 9-27 (2018)

5. W.-M.Wey, Sustainable Cities and Society 44, 275-290 (2019)

6. A.J. Pel, N. Agatz, C. Macharis, L.P. Veelenturf, Transportation Research Part C: Emerging Technologies 86, 168-170 (2018)

7. Y. Shi, T. Arthanari, X. Liu, et.al. Journal of Cleaner Production 212, 1381-1395 (2019)

8. J. Zheng, N.W. Garrick, C. Atkinson-Palombo, Ch. McCahill, W. Marshall, Research in Transportation Business \& Management 7, 4-13 (2013)

9. H. Wang, Y. Liu, W. Xiong, J. Song, International Journal of Project Management 37(1), 117-130 (2019)

10. F. Villalba-Romero, Ch. Liyanage, Case Studies on Transport Policy 3(2), 243-250 (2015)

11. I. Demirag, I. Khadaroo, The British Accounting Review 43(4), 294-310 (2011)

12. R. Macário, Research in Transportation Economics 30(1), 145-154 (2010)

13. F. Kurniawan, S. Wiwoho Mudjanarko et.al. Procedia Engineering 125, 124-132 (2015)

14. A. Bonnafous, Research in Transportation Economics 36(1), 45-49 (2012)

15. D. Meunier, E. Quinet, Research in Transportation Economics 30(1), 126-138 (2010)

16. R. Osei-Kyei, A.P.C. Chan, International Journal of Project Management 33(6), 1335 1346 (2015)

17. Y. Van Fan, S. Perry, J. Jaromír Klemeš, Ch. Tin Lee, Journal of Cleaner Production 194, 673-684 (2018)

18. L. Steg, R. Gifford, Journal of Transport Geography 13(1), 59-69 (2005)

19. W. Wang, G. Wets, Y. Shen, Electromobility for Green Transportation Systems and Sustainable Environment, Transportation Research, Part D: Transport and Environment (2018)

20. E.M. Generalova, V.P. Generalov, A.A. Kuznetsova, Procedia Engineering 153, $167-$ 172 (2016) 